\title{
Understanding and teaching English-language learners
}

\author{
Michael F. Opitz, Jenni L. Harding-DeKam
}

$\mathrm{T}$ This is it: my last column offering teachers current resources to inform teaching. Given the increasingly diverse school populations and as a result of working with countless novice and practicing teachers, both Jenni and I (Michael) realize that one recurring topic warrants attention: understanding and teaching English-language learners (i.e., students who speak one or more other languages and are learning English).

Without a doubt, all students have a primary language. The problem is that their first language may not match the dominant language used in their school. So what is a teacher supposed to do? Imagine, for example a parent-teacher conference I (Jenni) experienced where the parents spoke Russian and I did not. There was no interpreter present, making communication one-sided because the language barrier could not be broken. We wanted to make a difference in this child's education, but we had no common ground on which to build. Fortunately, since that time there have been several helpful resources written and published to help teachers and administrators who are grappling with ways to best understand and teach English-language learners (ELLs).

Of the many available books, Jenni and I chose to review recently published books that are easily accessible - they can be purchased online or at the local bookstore. The authors' writings are concise and the books encourage teachers to think about how they might best help all learners to maximize their full literacy potential. Finally, the authors base their ideas on current theories about how best to instruct ELLs.

The first three books in particular offer much background information and teaching suggestions for those who are just beginning to understand how to help ELLs. Succeeding With English Language Learners: A Guide for Beginning Teachers by Thomas Farrell (2006) provides first-year teachers with considerations to think through. He then offers several suggestions for writing lesson plans geared toward helping ELLs succeed. He also provides some ideas for classroom management designed to keep students meaningfully engaged. Beyond this general information, specific chapters focus on teaching ELLs grammar, writing, speaking, reading, and listening. Finally, the author has several suggestions for assessing language and ideas for professional development. Farrell invites interaction by providing numerous "exploratory breaks" within the book, with the purpose of helping readers further internalize what they have just read by talking or writing about it.

Comprehension Strategies for English Language Learners by Margaret Bouchard (2005) is a second resource that provides research-based reading strategy lessons to help students better comprehend texts regardless of content area. After providing some information about how the reading strategies relate to the Teachers of English to Speakers of Other Languages Goals and Standards, a rationale for why these particular strategies need teaching, and a general explanation about how to teach the strategies, Bouchard offers some considerations for selecting and teaching the strategies to ELLs. She then provides a two-page chart that shows the stages of language development and cultural adaptation as well as linguistic considerations, cultural considerations, teaching suggestions, appropriate questioning techniques, and effective activities for each stage. In addition to three informal inventories teachers can use to better understand students and design appropri- 
ate lessons, Bouchard provides lesson plans for 30 reading strategies that include the purpose, benefits for ELLs, and specific teaching procedures. Not to be missed is the research base and the sample progress indicator for each strategy.

In Help! My Kids Don't All Speak English: How to Set Up a Language Workshop in Your Linguistically Diverse Classroom, Nancy Akhavan (2006) explicitly explains the process of educating students through content, context, and culture. She explains the nuts and bolts of the language workshop and suggests how to teach linguistically diverse students using unit-ofdesign worksheets with examples from multiple topics at various grade levels. Akhavan offers lesson strategies and assessment ideas, showing student work and classroom examples. She provides appendix sections of graphic organizers and book lists organized by units of study, such as literature with cultural viewpoints, family and belonging, simple language books, resiliency, change, and rights.

Sometimes we can best understand how to apply what we know by reading how others have implemented ideas. Reading their stories can often breathe life into ideas and instill a sense of confidence to forge ahead. In Supporting English Language Learners, Farin Houk (2005) provides some background information and then details how to create a school-wide climate and plan that focuses on how best to teach ELLs. She uses stories of teachers' experiences to provide this information, enabling readers to better understand her explanation. Beyond ideas for creating a context conducive to risk-free learning, Houck provides some advocacy ideas for those who need to convince others of the value in what they are doing.

In Ladybugs, Tornadoes, and Swirling Galaxies: English Language Learners Discover Their World Through Inquiry, Brad Buhrow and Anne Upczak Garcia (2006) demonstrate nonfiction inquiry as a tool for biliterate understanding of text comprehension and knowledge of reading strategies and skills. The authors share a look into their classrooms where they use critical pedagogy as a guide to develop thinking dispositions through inquiry and investigations. You won't want to miss the abundance of student and classroom examples that breathe excitement into teaching ELL students.

“The Words Came Down!' by Emellie Parker and Tess Pardini (2006) is the story of how one school's staff committed to working with students of all ages. The authors describe how they went about setting up their classroom with students' assistance to bring meaning to the environment. They also provide a detailed discussion of how they use workshops as a structure to support and nourish ELLs across the curriculum so that students develop language in different contexts. After listing and explaining workshop attributes, Parker and Pardini then provide separate chapters to showcase how specific workshops play out: writing workshop, reading workshop, social studies workshop, math workshop, science workshop. Student samples and pictures sprinkled throughout bring even greater understanding to many of the points the authors make.

We found two recent books that focus on teaching writing to ELLs. The first is Teaching Reading and Writing in Spanish and English in Bilingual and Dual Language Classrooms by Yvonne and David Freeman (2006). The Freemans provide teachers with a research-based approach to helping students become biliterate. The authors provide a historical overview of reading instruction in Spanish and English with an analysis and evaluation of each method. They also include extended scenarios of effective reading instruction organized around themes, as well as bibliographies of literature and content area books in both Spanish and English. Additionally, the Freemans suggest and outline an effective way to teach writing and provide students' samples that showcase the different stages of writing development in each language. They also suggest teaching strategies that teachers can implement at each writing stage.

The myths about ELL writers are dispelled in When English Language Learners Write: Connecting Research to Practice, $K-8$ by Katharine Davies Samway (2006). She expands on how to teach students in their native language and English using current research as a base. Samway explains how gender, race, ethnicity, and social class intersect with writing. A chart on reflective writing gives purposes and features for different types of written reflections. She demonstrates how this works in the classroom through an explicit approach to writing and its underlying philosophy. She explores the environment of students' writing to help establish classroom, school, and community influences.

In a more general sense, there are some teacher resources that serve as ongoing references. Balancing Reading and Language Learning by Mary Cappellini 
(2005) is one such resource, which is divided into five parts. Part one contains three chapters that provide information about ways that we can get to know students. Part two contains two chapters that explain ways to establish and teach shared, guided, and independent reading; use read-alouds to model language and reading strategies; and plan thematically. In part three, the author hones in on read-alouds and shared reading, providing specific children's literature titles appropriate for each. Guided reading is the focus for part 4 . The author elaborates on general ideas related to guided reading and proceeds to explain how to use it with students at different stages of reading (i.e., emergent, early, early fluent, and fluent). Part five focuses on independent reading, literature circles, and individual instruction. What's more is that Cappellini includes seven appendixes, each providing specific book lists or forms that can be reproduced and used as appropriate.

Supporting the Literacy Development of English Learners: Increasing Success in All Classrooms, edited by Terrell Young and Nancy Hadaway (2006), is a collection of well-researched chapters by 18 individual authors. Young and Hadaway begin with background for understanding the special needs of supporting ELLs in your classroom for section one. They focus the second section on strategies to help you differentiate curriculum and planning for diverse proficiency levels of ELLs. In the third section, the authors address reading instruction through comprehension strategies, vocabulary development, guided reading, and expository text structures. And the last section offers strategies for teaching oral and written language, including poetry performance and literature circles. There is a multitude of practitioner strategies to help teachers educate ELLs in language and literacy skills in the classroom.

Teaching English Learners: Strategies and Methods by Lynne Díaz-Rico (2004) presents comprehensible coverage of second language acquisition issues and techniques through basic principles, practices, and methods from the philosophical foundations of education. Díaz-Rico takes a holistic view of ELLs, with an in-depth look at the effects of culture on schooling, the cultural practices of schooling, and the sociopolitical context of education. She emphasizes a commitment to social justice for all students through chapters on building a community of learners, learning English through service to the community, culturally based language teaching, discourse, and dual-language proficiency. DíazRico includes an appendix on influencing language policy to benefit ELLs at various levels-classroom, school, school district, professional organizations, public opinion, state, federal, and national.

IRA Literacy Study Groups English Learners Module (International Reading Association, 2004) gives a comprehensive overview of teaching literacy to these students. This kit has everything needed for a book study leader or reading coach, with professional resources and a flexible framework for discussion. The collection has a facilitator's guide by Joan Irwin with ideas for creating your literacy study group, reproducible forms, teacher research, professional resources, and related journal articles and books for further information. English Learners: Reaching the Highest Level of English Literacy edited by Gilbert García (2003) serves as the main study book in the module, organized into sections of teaching English learners to read - current policy and best instructional practice, teaching English language developmentrethinking and redesigning curriculum, and optimizing culture as a bridge to literacy learning. All research is based on examinations of original theorists and current practitioners in the area of ELLs.

Finally, Windows to Language, Literacy, and Culture: Insights From an English-Language Learner by Cynthia Brock and Taffy Raphael (2005) also caught our attention. Of all the books about ELLs, what makes this one unique is that readers get insights on what it is like to be an ELL through the eyes of Deng, a fifth-grade student who is a Hmong ELL from Laos. The authors explain their research methodology and the insights they gain as a result of it. They provide a wealth of professional titles pertaining to specific topics sprinkled throughout the chapters. Brock and Raphael offer numerous reflection points throughout the text making this book an excellent choice for those who participate in book discussion groups.

These are few of the many titles available that can help us to provide meaningful instruction to English Language Learners. As you might infer from reading this column, one overriding theme is that possessing multiple languages makes students different, not deficient. Understanding how to capitalize on students' strengths puts us in a better position to teach them English, the dominant language used in most schools in the United States. 


\section{Guest coauthor Harding-DeKam also teaches at the University of Northern Colorado, Greeley, Colorado, USA.}

\section{References}

Akhavan, N.L. (2006). Help! My kids don't all speak English: How to set up a language workshop in your linguistically diverse classroom. Portsmouth, NH: Heinemann.

Bouchard, M. (2005). Comprehension strategies for English language learners. New York: Scholastic.

Brock, C.H., \& Raphael, T.E. (2005). Windows to language, literacy, and culture: Insights from an English-language learner. Newark, DE: International Reading Association.

Buhrow, B., \& Garcia, A.U. (2006). Ladybugs, tornadoes, and swirling galaxies: English language learners discover their world through inquiry. Portland, ME: Stenhouse.

Cappellini, M. (2005). Balancing reading and language learning: A resource for teaching English language learners, K-5. Portland, ME: Stenhouse; Newark, DE: International Reading Association.

Díaz-Rico, L.T. (2004). Teaching English learners: Strategies and methods. Boston: Pearson Education.

Farrell, T.S.C. (2006). Succeeding with English language learners: A guide for beginning teachers. Thousand Oaks, CA: Corwin.

Freeman, Y.S., \& Freeman, D.E. (2006). Teaching reading and writing in Spanish and English in bilingual and dual language classrooms (2nd ed.). Portsmouth, $\mathrm{NH}$ : Heinemann.

García, G.G. (2003). English learners: Reaching the highest level of English literacy. Newark, DE: International Reading Association.

Houk, F.A. (2005). Supporting English language learners: $A$ guide for teachers and administrators. Portsmouth, NH: Heinemann.

International Reading Association. IRA Literacy Study Groups English Learners Module. (2004). Newark, DE: Author.

Parker, E.L., \& Pardini, T.H. (2006). "The words came down!": English language learners read, write, and talk across the curriculum, K-2. Portland, ME: Stenhouse.

Samway, K.D. (2006). When English language learners write: Connecting research to practice, $\mathrm{K}-8$. Portsmouth, NH: Heinemann.

Young, T.A., \& Hadaway, N.L. (2006). Supporting the literacy development of English learners: Increasing success in all classrooms. Newark, DE: International Reading Association.

Instructional and Professional Materials Reviews features reviews of books that support teacher development in literacy education. All correspondence can be sent to the column editor, Michael F. Opitz, University of Northern Colorado, College of Education, McKee 216, Greeley, C0 80639, USA. 
Copyright of Reading Teacher is the property of International Reading Association and its content may not be copied or emailed to multiple sites or posted to a listserv without the copyright holder's express written permission. However, users may print, download, or email articles for individual use. 